\title{
A chelating agent system for the removal of barium sulfate scale
}

\author{
Zhifeng Luo $^{1} \cdot$ Nanlin Zhang ${ }^{1} \cdot$ Liqiang Zhao $^{1} \cdot$ Chunlei Wang ${ }^{2} \cdot$ Lin Wu $^{1} \cdot$ Pingli Liu ${ }^{1} \cdot$ Hongyu Ji ${ }^{1}$
}

Received: 15 October 2019 / Accepted: 8 April 2020 / Published online: 15 April 2020

(c) The Author(s) 2020

\begin{abstract}
This study aimed to prepare a chelating agent SA-20 using diethylenetriaminepentaacetic acid (DTPA) and low molecular weight sodium polyacrylate raw material for the removal of barium sulfate $\left(\mathrm{BaSO}_{4}\right)$ scale. The morphology of the resulting chelating agent was characterized by scanning electron microscopy. The $\mathrm{BaSO}_{4}$ scale removal ability of SA-20 was comprehensively evaluated by the dissolving ability, particle size analysis, corrosion performance, and fracture conductivity before and after the scale removal. The results showed that the SA-20 has a good $\mathrm{BaSO}_{4}$ scale removal ability due to the chelation, lattice distortion, and dispersion of DTPA and low molecular weight sodium polyacrylate.
\end{abstract}

Keywords Chelating agent $\cdot$ Corrosion ability $\cdot$ Dissolving ability $\cdot$ DTPA $\cdot$ Particle size analysis $\cdot$ Sodium polyacrylate

\section{Introduction}

With the development of the global oil and gas industry, higher requirements are put forward for drilling and stimulation (Luo et al. 2019). Barite, whose main constituent was barium sulfate $\left(\mathrm{BaSO}_{4}\right)$, was usually added into a drilling fluid as a weighting material to increase the fluid density of a drilling fluid (Elshreef and Lashin 2016; Fang et al. 2018; Nguyen et al. 2011; Srungavarapu et al. 2018). During drilling, most drilling fluid was lost and entered the reservoir, and solid particles, such as $\mathrm{BaSO}_{4}$, were deposited in the reservoir, resulting in the damage of the reservoir (Al-Yami et al. 2010; Bozau et al. 2015; Liu et al. 2017; Mozaffari et al. 2015, 2017b; Shahbazi et al. 2006). Thus, it is important to develop a chelating system for the removal of the $\mathrm{BaSO}_{4}$ scale. At present, the development of the chelating agent mainly focused on a slightly soluble sulfate scale-dissolving agent (Egermann et al. 2002). Scale-removing agents

Nanlin Zhang

nanlin_zhang@163.com

$\triangle$ Liqiang Zhao

Zhaolq@vip.163.com

1 State Key Laboratory of Oil and Gas Reservoir Geology and Exploitation, Southwest Petroleum University, Chengdu 610500, China

2 Downhole Operation Department of Natural Gas Business Department, Petrochina Tarim Oilfield Company, Korla 841000, Xinjiang, China usually had a compound formula composed of an organic complexing agent (Balanyà et al. 2018), scale inhibitor (Yan et al. 2015; Zhang et al. 2016), surface surfactant (Ratkievicius et al. 2016), and so on. Recently, the study of scaleremoving agents focused on aminocarboxylate chelating agent (Uchida et al. 2001). This agent is a kind of carboxylic acid derivative with the main body of aminocarboxylic acid. It could form a stable and water-soluble chelating product easily with many metal ions and thus was widely used for the chemical treatment of slightly soluble scale, which mostly contained salts of $\mathrm{Ca}, \mathrm{Mg}, \mathrm{Ba}$, and $\mathrm{S}$ (Shaw and Sorbie 2015). Besides chelation and dissolution of the scale, an aminocarboxylate chelating agent could wet, disperse, and destroy hard scale blocks, which could be changed to loose scale soil. Generally, the larger the stability constant of the aminocarboxylate chelating agent, the stronger the dissolution ability on the salt scale (Gál et al. 2013).

Many studies have been conducted on the blocking removal of a slightly soluble sulfate salt scale, emphasizing the use of aminocarboxylate chelating agents such as representative DTPA and EDTA (Ethylenediaminetetraacetic acid) (A.P. Abib et al. 2018). Despite many successful applications in the $\mathrm{BaSO}_{4}$ scale removal task of many oil fields, many cases were only applied in the ground pipeline at room temperature or shallow reservoir (Elkatatny 2019; Jin et al. 2014; Mahmoud et al. 2018; Wang et al. 2017). Studies on the development of a cleaning agent for deep layers under high temperature and high pressure are scarce. Thus, this study proposed a chelating system SA-20 for the removal of the $\mathrm{BaSO}_{4}$ scale 
under the aforementioned conditions. A system composed of the main agent of DTPA, which was dissolved in sodium hydroxide $(\mathrm{NaOH})$ solution at a $\mathrm{pH}$ of 12 , and the adjuvant of low molecular weight sodium polyacrylate was prepared. The performance of SA-20 was evaluated by surface morphology analysis, weight change test, particle size analysis, corrosion performance, and fracture conductivity.

\section{Experimental}

\section{Material}

DTPA, sodium polyacrylate, $\mathrm{BaSO}_{4}, \mathrm{NaOH}$, acetone, ethanol, and ammonium chloride $\left(\mathrm{NH}_{4} \mathrm{Cl}\right)$ were of analytical grade and purchased from Chengdu Kelon Chemical Reagent Company of China. The main constituents of steel disks of N80 and $13 \mathrm{Cr}$ (About $50103 \mathrm{~mm}^{3}$ ) are shown in Tables 1 and 2, respectively.

The prepare method of SA-20 is: Measuring a certain amount of distilled water into the beaker, adjust the $\mathrm{pH}$ value to 8 with sodium hydroxide, weighing a certain amount of DTPA (Depending on the experimental parameters), slowly add it into the distilled water, stir continuously when adding DTPA, after DTPA dissolves, add a certain amount of sodium polyacrylate (Depending on the experimental parameters), fully mix and dissolve.

\section{Instruments}

The following instruments were used in this study: ZF-9 electronic analytical balance $( \pm 0.1 \mathrm{mg}$, Shanghai Tetragonal Electronic Instrument Factory, China), YHG-9050A thermostatic blast dryer $\left( \pm 1^{\circ} \mathrm{C}\right.$, Shanghai Yaoshi Instrument and Equipment Factory, China), HELOS-GRADIS Laser Particle Size Meter ( $\pm 1 \%$, SYMPATEC GMBH, Germany), scanning electron microscope (SEM, JSM-7500F produced by JEOL), and fracture conductivity instrument (Haian Petroleum Research Instruments Co., Ltd., China).

\section{Experimental methods}

\section{Surface morphology analysis}

The micromorphology of the product formed by the chelating agent system SA-20 and $\mathrm{Ba}^{2+}$ was characterized by SEM.
Table 2 Composition of $13 \mathrm{Cr}$ steel (weight fraction)

\begin{tabular}{lllll}
\hline Element & $\mathrm{C}$ & $\mathrm{Si}$ & $\mathrm{Mn}$ & $\mathrm{Cr}$ \\
\hline Content $(\%)$ & 0.2 & 0.23 & 0.44 & 13 \\
\hline
\end{tabular}

\section{Dissolving ability measured by weight change}

A certain amount of $\mathrm{BaSO}_{4}$ was weighed into the reaction kettle. Then, a certain amount of SA-20 was also added to it. The reaction kettle was put into the electric drying oven with forced convection and allowed to stand for a while at a specific temperature. Finally, the residue of the reaction was filtered and dried at $80 \mathrm{C}$ for $24 \mathrm{~h}$. The dissolving ability was calculated using the following equation:

$D_{R}=\frac{m_{p}-m_{n}}{V}$

where $D_{R}(\mathrm{~g} / \mathrm{L})$ is the dissolving ability of SA-20; $m_{p}(\mathrm{~g})$ is the total weight of $\mathrm{BaSO}_{4}$ and the filter paper before the reaction; $m_{n}(\mathrm{~g})$ is the total weight of $\mathrm{BaSO}_{4}$ and the filter paper after the reaction, filtering, and drying; and $V$ is the SA-20 volume.

\section{Particle size analysis}

The particle size distribution of a certain amount of $\mathrm{BaSO}_{4}$ was measured and put into the reaction kettle. A certain amount of SA-20 was also put into the reaction kettle. The reaction kettle was put into the electric drying oven with $4 \mathrm{~h}$ of chemical reaction at $150^{\circ} \mathrm{C}$, and the residue of the reaction was filtered and dried at $80 \mathrm{C}$ for $24 \mathrm{~h}$. The particle size distribution of $\mathrm{BaSO}_{4}$ that permeated and did not permeate the filter paper after the reaction was measured.

\section{Corrosion ability}

Steel disks of $\mathrm{N} 80$ and $13 \mathrm{Cr}$ were washed with acetone and ethanol, dried, and weighed. After immersing into SA-20 for $10 \mathrm{~h}$ at $90 \mathrm{C}$, the steel disks were taken out, washed with distilled water, acetone, and ethanol, dried, and weighed. The corrosion ability $C_{R}$ was calculated using the following equation:

$C_{R}=\frac{m_{p}^{\prime}-m_{n}^{\prime}}{t S}$

where $C_{R}\left(\mathrm{~g} \mathrm{~h}^{-1} \mathrm{~m}^{-2}\right)$ is the corrosion ability; $m_{p}^{\prime}(\mathrm{g})$ is the steel disk weight before corrosion; $m_{n}^{\prime}(\mathrm{g})$ is the steel disk
Table 1 Composition of N80 steel (weight fraction)

\begin{tabular}{lllllllll}
\hline Element & $\mathrm{C}$ & $\mathrm{Si}$ & $\mathrm{Mn}$ & $\mathrm{P}$ & $\mathrm{S}$ & $\mathrm{Cr}$ & $\mathrm{V}$ & $\mathrm{Al}$ \\
\hline Content (\%) & 0.34 & 0.22 & 1.55 & 0.18 & 0.013 & 0.14 & 0.13 & 0.02 \\
\hline
\end{tabular}


weight after corrosion; $t(\mathrm{~h})$ is the duration of corrosion; and $S\left(\mathrm{~m}^{2}\right)$ is the surface area of the steel disk.

\section{Flow conductivity test before and after the removal of $\mathrm{BaSO}_{4}$}

The flow conductivity experiment was performed using the fracture conductivity instrument. The theoretical analysis of conductivity experiment was carried out as follows: Two 7-cm-long cores with a diameter of $2.54 \mathrm{~cm}$ were slit along the axis. The $\mathrm{BaSO}_{4}$ particles were spread over one of the profiles of the core to simulate the blocking of $\mathrm{BaSO}_{4}$ in microfracture in the reservoir stratum (No. A1). A depth of $100 \mathrm{~m}$ fine screens was put first on another core. Then, the $\mathrm{BaSO}_{4}$ powder was spread over it to simulate the $\mathrm{BaSO}_{4}$ blocking in a broad fracture in the reservoir stratum (No. A2). The aforementioned cores were put into the core holder. Then, $3 \% \mathrm{NH}_{4} \mathrm{Cl}$ base solution, $\mathrm{SA}-20$, and $3 \% \mathrm{NH}_{4} \mathrm{Cl}$ base solution were injected into the core holder sequentially. The change in the permeability during the injecting process was measured.

\section{Results and discussion}

\section{Surface morphology}

The morphology after the chelation of SA-20 and $\mathrm{Ba}^{2+}$ was characterized by SEM. The characterization result is shown in Fig. 1.

SA-20 could form a stable chelating product with $\mathrm{Ba}^{2+}$. The chelating ability of the main agent DTPA was strong, resulting in the chelating product with high stability constant. Multiple ligands provided multiple pairs of electrons to form coordination bonds with the metal ion $\mathrm{Ba}^{2+}$ at the center. The chelating product with the structure of a five or six membered ring was much more stable than the ordinary coordination compound (Mozaffari et al. 2017a).

\section{Dissolving ability}

\section{Influence of $\mathrm{pH}$ on the dissolving ability}

Figure 2 shows the dissolving ability of SA-20 on $\mathrm{BaSO}_{4}$ at different $\mathrm{pH}$ values.

The influence of $\mathrm{pH}$ on the dissolving ability of SA-20 was large. The dissolving ability continued to increase with increasing $\mathrm{pH}$, reached the maximum at $\mathrm{pH} 12$, and then slowly decreased with a further increase of $\mathrm{pH}$. This was because the carboxyl group mainly existed in the form of

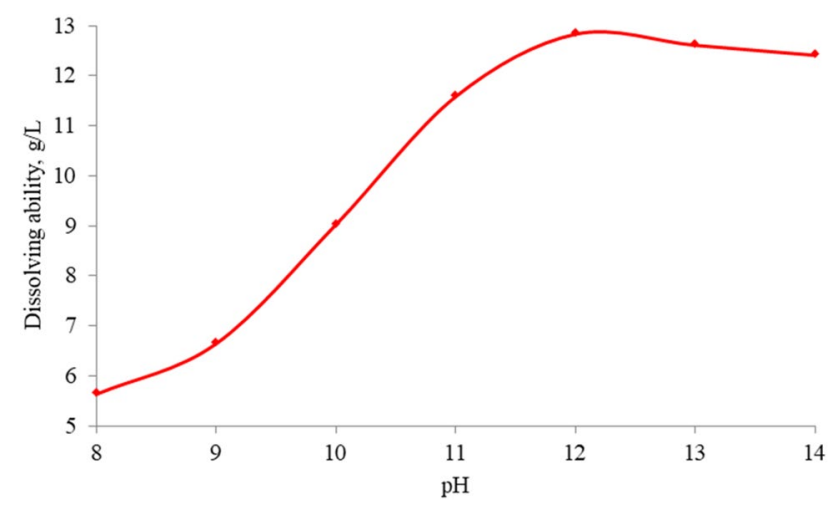

Fig. 2 The dissolving ability of SA-20 on BaSO4 at different $\mathrm{pH}$ values

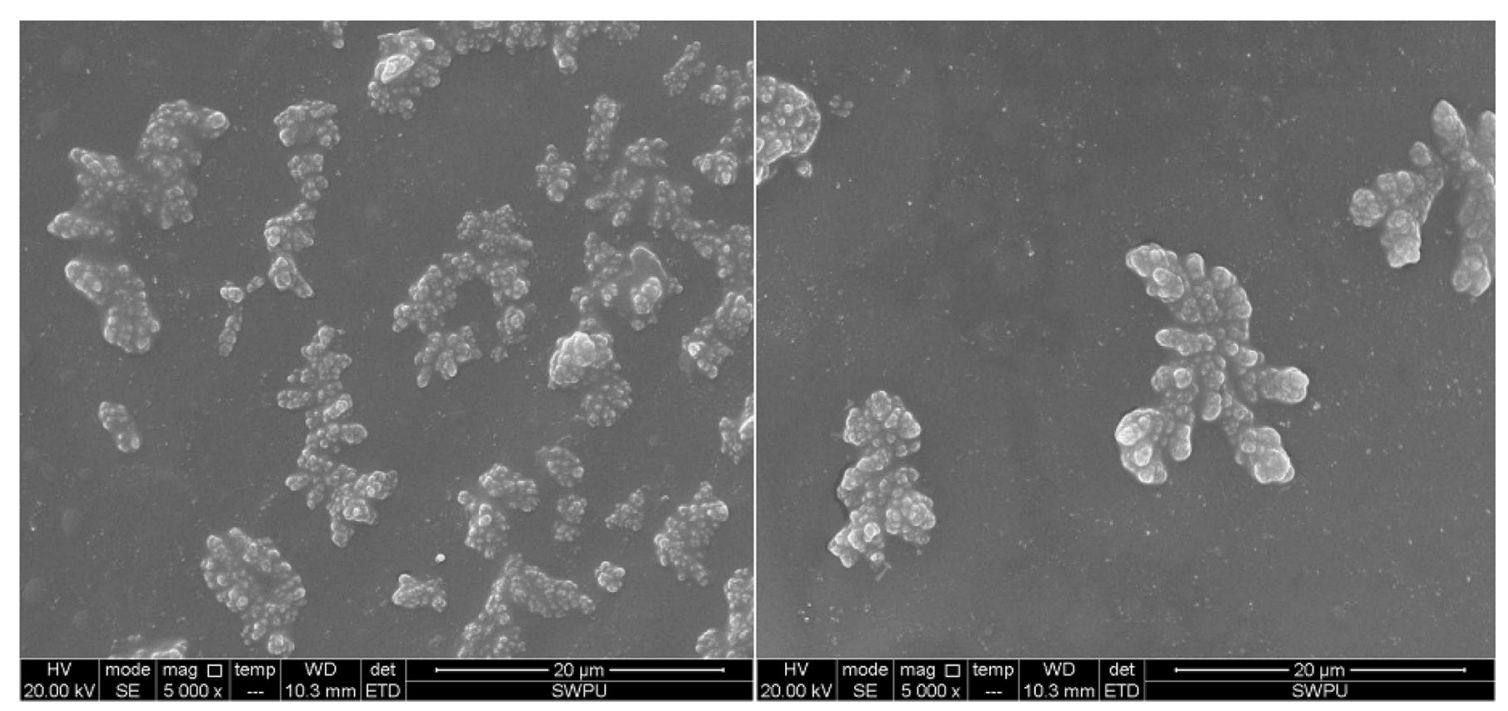

Fig. 1 The product formed by the chelation of SA-20 and $\mathrm{Ba}^{2+}$ 
- $\mathrm{COOH}$ in the DTPA molecule under weak alkaline condition, limiting the chelating performance with $\mathrm{Ba}^{2+}$. With a gradual increase in $\mathrm{pH}, \mathrm{H}^{+}$of the carboxyl group ionized to form $-\mathrm{COO}^{-}$, which could strongly chelate with $\mathrm{Ba}^{2+}$. Thus, the dissolving ability increased. However, under the strong alkaline condition with overlarge $\mathrm{pH}$, metal hydroxide was formed and crystallized to influence the chelation with $\mathrm{Ba}^{2+}$, decreasing the dissolving ability.

\section{Influence of sodium polyacrylate concentration on the dissolving ability}

Figure 3 shows the dissolving ability of SA-20 on $\mathrm{BaSO}_{4}$ at different concentrations of sodium polyacrylate.

The dissolving ability of SA-20 on $\mathrm{BaSO}_{4}$ increased initially, reached a maximum, and further decreased with the increase of the concentration of the adjuvant sodium polyacrylate. This was because large amounts of negative polyacrylate ions ionized from low molecular weight sodium polyacrylate were strongly adsorbed on the surface of $\mathrm{BaSO}_{4}$ particles, which thus possessed an identical negative charge. Other ions $\left(\mathrm{Na}^{+}\right)$with opposite charge freely diffused to the peripheral liquid medium to form a diffusion layer with charged ions, resulting in the electric double-layer structure with a certain electric potential. When the $\mathrm{BaSO}_{4}$ particles approached each other, particles with identical charge formed electric repulsion to maintain a certain distance between each other, which prevented the aggregation and flocculation of particles. Thus, the dispersion was realized, resulting in full contact between the main agent DTPA and $\mathrm{BaSO}_{4}$ particles as well as the complete reaction, which resulted in a high dissolving ability.

When a small amount of low molecular weight sodium polyacrylate was added, particles that were not surrounded by polyacrylate ion aggregated due to the electric attraction and decreased the contact area of DTPA and $\mathrm{BaSO}_{4}$ particles, resulting in incomprehensive reaction and low

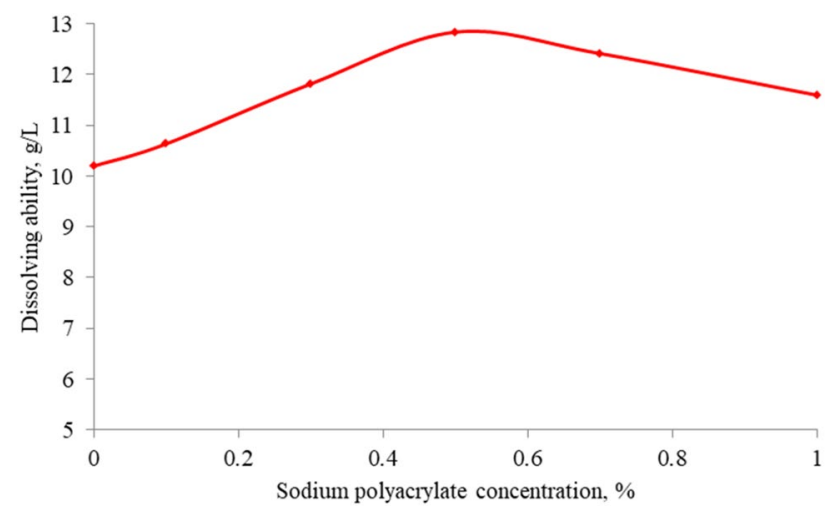

Fig. 3 Dissolving ability of SA-20 at different sodium polyacrylate concentrations dissolving ability. When the amount of low molecular weight sodium polyacrylate was too large, excessive polyacrylate ions led to the changes in the ionic environment in the dispersion solution; the interface adsorption reached saturation, and excessive hydrocarbon bonds flocculated through hydrophobic association to synthesize micelles, thereby reducing the contact area between DTPA and $\mathrm{BaSO}_{4}$ particles, resulting in insufficient reaction and low dissolution capacity.

\section{Influence of DTPA concentration on the dissolving ability}

Figure 4 shows the dissolving ability of SA-20 on $\mathrm{BaSO}_{4}$ with different concentrations of DTPA.

At $90{ }^{\circ} \mathrm{C}$, the $\mathrm{BaSO}_{4}$ dissolving ability of SA-20 increased initially, reached the maximum at a concentration of $6 \%$, and decreased with the continuous increase of the DTPA concentration. At $150{ }^{\circ} \mathrm{C}$, the $\mathrm{BaSO}_{4}$ dissolving ability of SA-20 increased initially, reached $15.87 \mathrm{~g} / \mathrm{L}$ at a concentration of $6 \%$, and then remained almost unchanged with the continuous increase of DTPA concentration due to the influence of threshold effect (Mahmoud et al. 2018). The small addition of DTPA could stably dissolve much $\mathrm{Ba}^{2+}$ in water, whereas the chelating performance did not increase dramatically or even decreased when exceeding a certain concentration.

\section{Influence of the reaction time on the dissolving ability}

Figure 5 shows the dissolving ability of SA-20 on $\mathrm{BaSO}_{4}$ at different reaction times.

At $90{ }^{\circ} \mathrm{C}$, due to the decrease in mass transfer rate in the reaction system, the dissolving ability was mainly influenced by reaction time. With the increase in time, the dissolving ability gradually increased initially and then reached a plateau. At $150{ }^{\circ} \mathrm{C}$, due to the fast mass transfer rate, the chelating product of the reaction could rapidly diffuse to the fluid system that was far from the $\mathrm{BaSO}_{4}$ solid surface. Thus, the

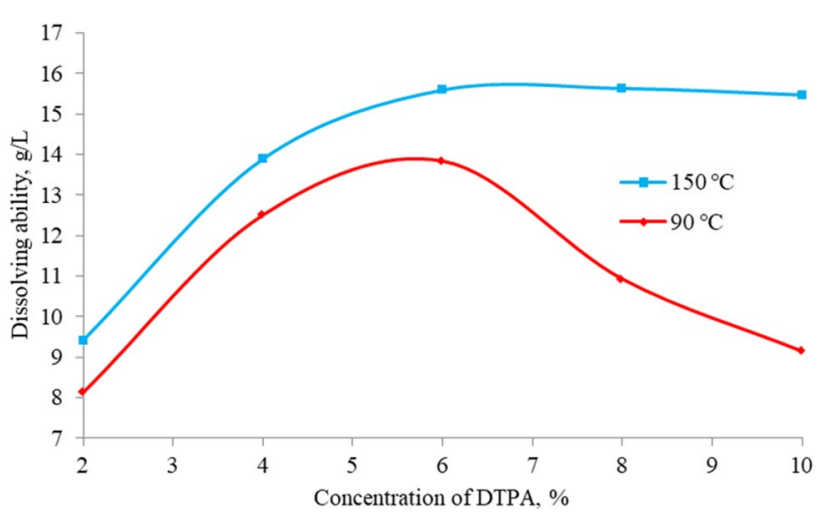

Fig. 4 Dissolving ability of SA-20 with different concentrations of DTPA 


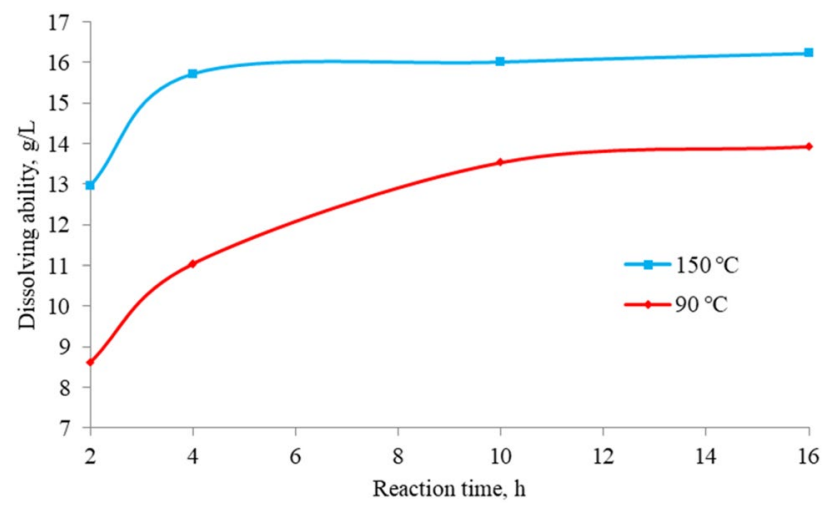

Fig. 5 Dissolving ability of SA-20 at different reaction times

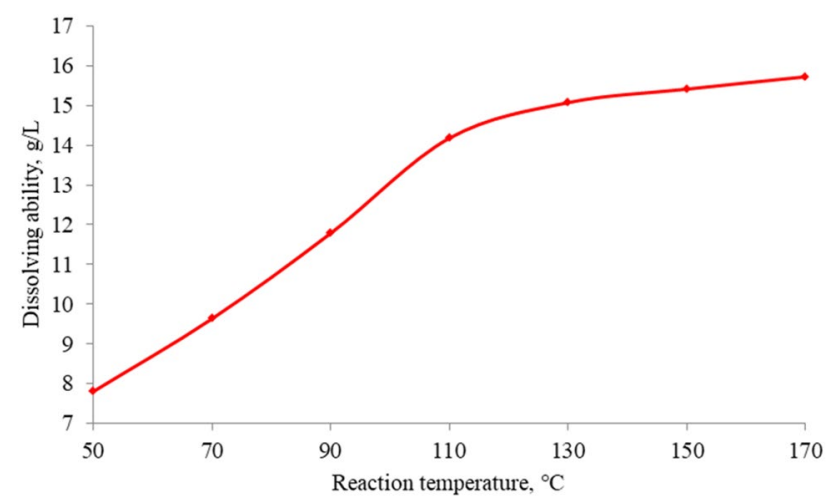

Fig. 6 Dissolving ability of SA-20 at different temperatures. a After the reaction. $\mathbf{b} 15$ days after the reaction

dissolving ability could reach the limit in a short time of $4 \mathrm{~h}$ and then remained constant afterward.

\section{Influence of temperature on the dissolving ability}

Figure 6 shows the dissolving ability of SA-20 on $\mathrm{BaSO}_{4}$ at different temperatures.

With the increase in the reaction temperature, the dissolving ability of SA-20 on $\mathrm{BaSO}_{4}$ increased initially, reached $14.2 \mathrm{~g} / \mathrm{L}$ at $110^{\circ} \mathrm{C}$, and then increased slowly with a small change due to the low stability constant $K_{\mathrm{sp}}$ of the chelating reaction at low temperature, which made the chelation of $\mathrm{Ba}^{2+}$ ion in the solution system not effective. However, when the reaction temperature increased to a certain extent, not only the stability constant $K_{\mathrm{sp}}$ but also the mass transfer rate increased, accelerating the chelating reaction and the dissolution of $\mathrm{BaSO}_{4}$. However, the stability constant $K_{\mathrm{sp}}$ did not increase without limit. Thus, the increasing change in the dissolving ability at temperatures between 150 and $170{ }^{\circ} \mathrm{C}$ was gradually small. Besides, the high temperature would not influence the dissolving ability of SA-20 due to the good stability of the blocking removal agent at high temperature.

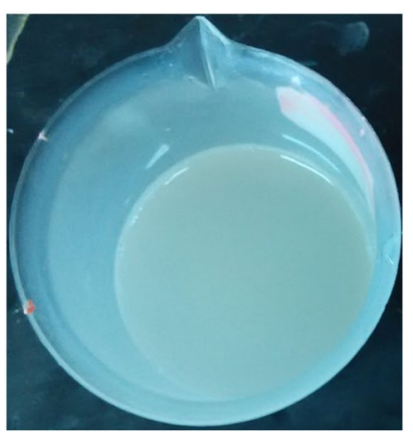

(a) After the reaction.

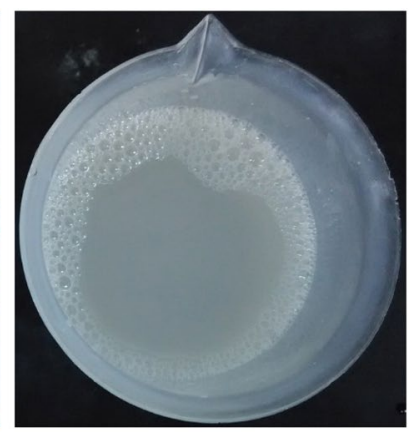

(b) 15 days after the reaction.
Fig. 7 Residue appearance after the reaction

Table 3 Influence of $\mathrm{Mg}(\mathrm{OH})_{2}$ and $\mathrm{CaCO}_{3}$ on the dissolving ability of SA-20

\begin{tabular}{llllll}
\hline No & Scale type & $\begin{array}{l}\text { Moles } \\
(\mathrm{mol})\end{array}$ & $\begin{array}{l}\text { Dissolving moles } \\
(\mathrm{mol})\end{array}$ & $\begin{array}{l}\text { Dis- } \\
\text { solving } \\
\text { amount } \\
(\mathrm{g})\end{array}$ & $\begin{array}{l}\text { Total dis- } \\
\text { solving } \\
\text { amount } \\
(\mathrm{g})\end{array}$ \\
\hline 1 & $\mathrm{Mg}(\mathrm{OH})_{2}$ & 0.025 & 0.01122 & 0.6508 & 2.5124 \\
& $\mathrm{CaCO}_{3}$ & 0.025 & 0.00555 & 0.5545 & \\
& $\mathrm{BaSO}_{4}$ & 0.025 & 0.00561 & 1.3071 & \\
2 & $\mathrm{CaCO}_{3}$ & 0.03 & 0.00825 & 0.825 & 3.144 \\
& $\mathrm{BaSO}_{4}$ & 0.03 & 0.00995 & 2.319 & \\
\hline
\end{tabular}

No impurity of either floccules or precipitate was observed after 15 days of the residue following the reaction at high temperature (Fig. 7). This indicated that the blocking removal agent SA-20 possessed a good precipitation inhibition ability.

\section{Influence of other scales on the dissolving ability}

$\mathrm{Mg}(\mathrm{OH})_{2}$ and $\mathrm{CaCO}_{3}$ were common scales in the oil fields that were easier to be dissolved than $\mathrm{BaSO}_{4}$. Related experiments were conducted to study the influence of $\mathrm{Mg}(\mathrm{OH})_{2}$ and $\mathrm{CaCO}_{3}$ on the dissolving ability of SA-20. Table 3 shows the dissolving ability of SA-20 with the existence of $\mathrm{Mg}(\mathrm{OH})_{2}$ and $\mathrm{CaCO}_{3}$.

Because of the higher solubility of $\mathrm{Mg}(\mathrm{OH})_{2}$ under high temperature compared with $\mathrm{CaCO}_{3}$ and $\mathrm{BaSO}_{4}$, the ionized $\mathrm{Mg}^{2+}$ chelated with DTPA more easily. Thus, the dissolving ability of SA-20 in $\mathrm{Mg}(\mathrm{OH})_{2}$ was stronger than that of $\mathrm{CaCO}_{3}$ and $\mathrm{BaSO}_{4}$. Due to the higher polarity of $\mathrm{Ba}^{2+}$ compared with $\mathrm{Ca}^{2+}$, the dissolving ability of SA-20 in $\mathrm{BaSO}_{4}$ was slightly stronger than that of $\mathrm{CaCO}_{3}$. Besides, although $\mathrm{Mg}(\mathrm{OH})_{2}$ reacted with SA-20 more easily, $\mathrm{Mg}(\mathrm{OH})_{2}$, $\mathrm{CaCO}_{3}$, and $\mathrm{BaSO}_{4}$ reacted with SA-20 simultaneously and not sequentially. 
The analysis of the No. 2 scale sample showed that the advantage of the higher polarity of $\mathrm{Ba}^{2+}$ than $\mathrm{Ca}^{2+}$ became more dramatic with only $\mathrm{CaCO}_{3}$ and $\mathrm{BaSO}_{4}$ and without the competition of $\mathrm{Mg}^{2+}$; thus, $\mathrm{BaSO}_{4}$ reacted with the SA-20 more easily. In the field application, it was possible to pump a plug of acid solution to dissolve acid-soluble blockage of $\mathrm{Mg}(\mathrm{OH})_{2}$ and $\mathrm{CaCO}_{3}$ before the injection of SA-20. Thus, the blocking remover SA-20 could specifically solve the blocking problem of barite.

\section{$\mathrm{BaSO}_{4}$ particle size analysis}

The $\mathrm{BaSO}_{4}$ dissolution by SA-20 could smash a large block of $\mathrm{BaSO}_{4}$ scale into the small ones. Figures 8, 9, and 10 are the distribution curves of $\mathrm{BaSO}_{4}$ particles before reaction, $\mathrm{BaSO}_{4}$ particles that did not permeate, and those that permeated through the filter paper after the reaction, respectively. Table 4 shows cumulative particle size distributions of $10 \%$, $50 \%$, and $90 \%$ before and after the reaction.

The average particle size is about $2.7 \mu \mathrm{m}$ before adding the chelating agent, the average size of barite particles that did not permeate through the filter paper is about $1.8 \mu \mathrm{m}$ after adding the chelating agent, the average size of barite particles that permeate through the filter paper is about $1 \mu \mathrm{m}$ after adding the chelating agent. The particle size is mainly distributed between 0.4 and $1000 \mu \mathrm{m}$ before adding the chelating agent. The particle size of the barite particles that did not permeate through the filter paper is mainly distributed between 0.3 and $30 \mu \mathrm{m}$, and the particle size of the barite particles that permeate through the filter paper is mainly distributed between 0.15 and $5 \mu \mathrm{m}$ after adding the chelating agent.

The particle size of $\mathrm{BaSO}_{4}$ dramatically decreased after the reaction with SA-20. Some too small $\mathrm{BaSO}_{4}$ particles could even permeate through the quantitative filter paper slowly, illustrating the excellent ability to smash $\mathrm{BaSO}_{4}$ particles of SA-20. This was due to the physical and chemical adsorption of the dispersive agent sodium polyacrylate on the $\mathrm{BaSO}_{4}$ particle surface, which produced charge aggregation and the electric double layer around the particle surface. The resultant repulsion between particles made them suspended and dispersed. Thus, $\mathrm{BaSO}_{4}$ was dispersed

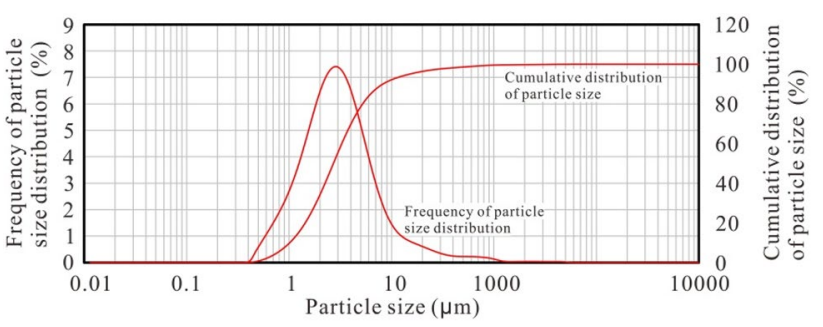

Fig. 8 Particle size distribution of $\mathrm{BaSO}_{4}$ before the reaction

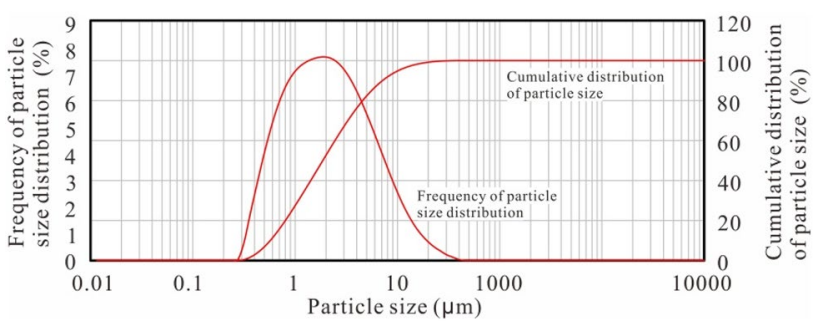

Fig. 9 Particle size distribution of $\mathrm{BaSO}_{4}$ that did not permeate through the filter paper after the reaction

and smashed. Besides, the particles dispersed in the system increase the contact area with SA-20, which greatly improves the reaction rate.

\section{Corrosion ability}

DTPA in SA-20 had a metal corrosion performance to some extent. The $\mathrm{N} 80$ and $13 \mathrm{Cr}$ corrosion ability of SA-20 was tested. Table 5 shows the $\mathrm{N} 80$ and $13 \mathrm{Cr}$ steel disk corrosion rate of SA-20, and Fig. 11 shows the appearance of the steel disk before and after the corrosion.

Almost no change was observed on the surface of N80 and $13 \mathrm{Cr}$ steel disks. The average N80 steel disk corrosion rate of SA-20 was only $0.1182 \mathrm{~g} \mathrm{~m}^{-2} \mathrm{~h}^{-1}$, whereas the average $13 \mathrm{Cr}$ steel disk corrosion rate was lower, only $0.0388 \mathrm{~g}$ $\mathrm{m}^{-2} \mathrm{~h}^{-1}$, which could fulfill the field usage requirement, with no adverse effect on tubing and casing.

\section{Flow conductivity ability test}

The $\mathrm{BaSO}_{4}$ blocking dissolution performance of SA-20 was measured using the fracture flow conductivity test before and after $\mathrm{BaSO}_{4}$ blockage dissolution in the fracture. Figure 12 shows the profile and the end surface morphology in microfracture before and after $\mathrm{BaSO}_{4}$ dissolution (No. A1). Figure 13 shows the morphology of the profile and the end surface in a broad fracture before and after $\mathrm{BaSO}_{4}$ dissolution (No. A2). The red line in Figs. 12 and 13 represents the

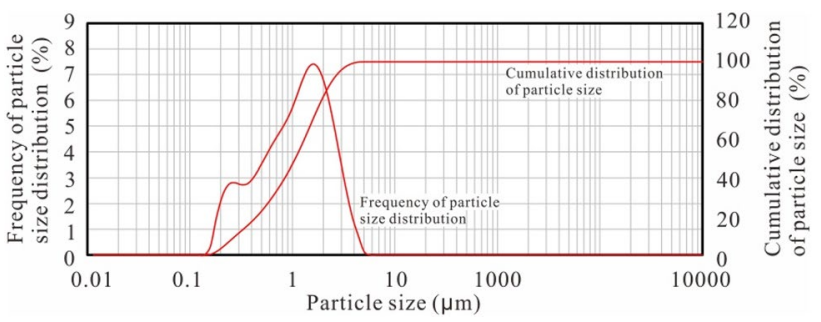

Fig. 10 Particle size distribution of $\mathrm{BaSO}_{4}$ that permeated through the filter paper after the reaction. a N80 steel disk before and after the corrosion. B $13 \mathrm{Cr}$ steel disk before and after the corrosion 
Table $4 \mathrm{BaSO}_{4}$ particle size before and after the reaction

\begin{tabular}{llll}
\hline & $\begin{array}{l}\mathrm{BaSO}_{4} \text { particle size } \\
\text { before the reaction }(\mu \mathrm{m})\end{array}$ & $\begin{array}{l}\mathrm{BaSO}_{4} \text { particle size that did not per- } \\
\text { meate through the filter paper }(\mu \mathrm{m})\end{array}$ & $\begin{array}{l}\mathrm{BaSO}_{4} \text { particle size that perme- } \\
\text { ated through the filter paper } \\
(\mu \mathrm{m})\end{array}$ \\
\hline $\mathrm{d}(0.1)$ & 1.013 & 0.570 & 0.279 \\
$\mathrm{~d}(0.5)$ & 2.706 & 1.861 & 1.071 \\
$\mathrm{~d}(0.9)$ & 8.226 & 7.150 & 2.437 \\
\hline
\end{tabular}

Table $5 \mathrm{~N}-80$ and $13 \mathrm{Cr}$ steel disk corrosion rate of SA-20

\begin{tabular}{|c|c|c|c|c|c|c|c|c|}
\hline Steel disktype & Tested diskNo & $\begin{array}{l}\text { Length } \\
(\mathrm{cm})\end{array}$ & $\begin{array}{l}\text { Width } \\
(\mathrm{cm})\end{array}$ & $\begin{array}{l}\text { Thickness } \\
(\mathrm{cm})\end{array}$ & $\begin{array}{l}\text { Weight before } \\
\text { the corrosion } \\
\text { (g) }\end{array}$ & $\begin{array}{l}\text { Weight after the } \\
\text { corrosion }(\mathrm{g})\end{array}$ & $\begin{array}{l}\text { Corrosionrate }(\mathrm{g} \\
\left.\mathrm{m}-{ }^{2} \mathrm{~h}^{-1}\right)\end{array}$ & $\begin{array}{l}\text { Aver- } \\
\text { agecorro- } \\
\text { sionrate } \\
\left(\mathrm{g} \cdot \mathrm{m}^{2} \cdot \mathrm{h}^{-1}\right)\end{array}$ \\
\hline \multirow[t]{2}{*}{ N80 } & 254 & 4.91 & 0.97 & 0.30 & 10.8766 & 10.8751 & 0.1128 & \multirow[t]{2}{*}{0.1182} \\
\hline & 998 & 4.92 & 0.98 & 0.23 & 10.7277 & 10.7261 & 0.1236 & \\
\hline \multirow[t]{2}{*}{$13 \mathrm{Cr}$} & 102 & 4.98 & 1.11 & 0.22 & 11.4511 & 11.4506 & 0.0354 & \multirow[t]{2}{*}{0.0388} \\
\hline & 185 & 4.94 & 1.04 & 0.38 & 11.5846 & 11.5840 & 0.0422 & \\
\hline
\end{tabular}
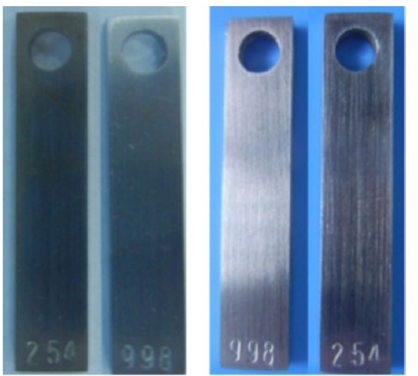

(a) N80 steel disk before and after the corrosion.

Fig. 11 Appearance of steel disks before and after corrosion. a Before $\mathrm{BaSO}_{4}$ dissolution. b After $\mathrm{BaSO}_{4}$ dissolution

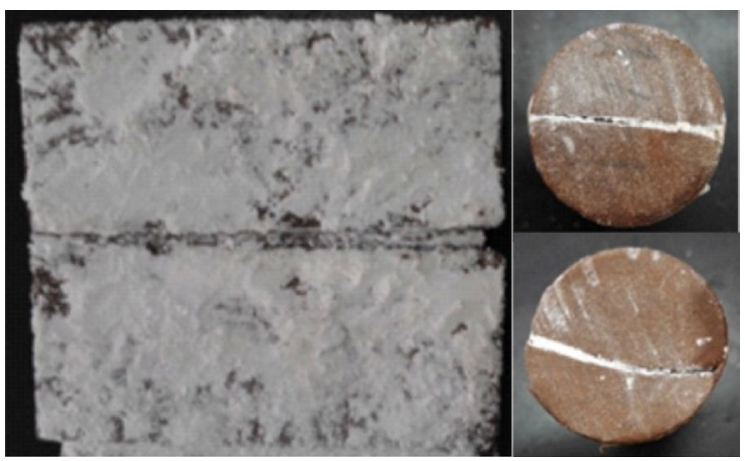

(a) Before $\mathrm{BaSO}_{4}$ dissolution. oil and gas flow path formed by the dissolution of $\mathrm{BaSO}_{4}$. Figure 14 shows the flow conductivity change curve in microfracture before and after $\mathrm{BaSO}_{4}$ dissolution (No. A1). Figure 15 shows the flow conductivity ability change in a broad fracture before and after $\mathrm{BaSO}_{4}$ dissolution (No. A2). The $y$-axis represents the ratio of fracture permeability to initial permeability in the experimental process, and the abscissa represents the ratio of the cumulative volume of injected liquid to fracture volume in Figs. 14 and 15.

Figure 12 and Fig. 13 indicate that after thorough wetting, chelating, and dispersion, $\mathrm{BaSO}_{4}$ in fracture was gradually dissolved, dispersed, and brought out. A flowing passage was formed apparently by the corrosion and scouring of $\mathrm{BaSO}_{4}$ in the profile of the fracture, greatly increasing the permeability of the fracture. Figures 14 and 15 indicate that after injecting of SA-20 into A1 and A2 cores, the permeability recovery rate was 340 and $590 \%$,

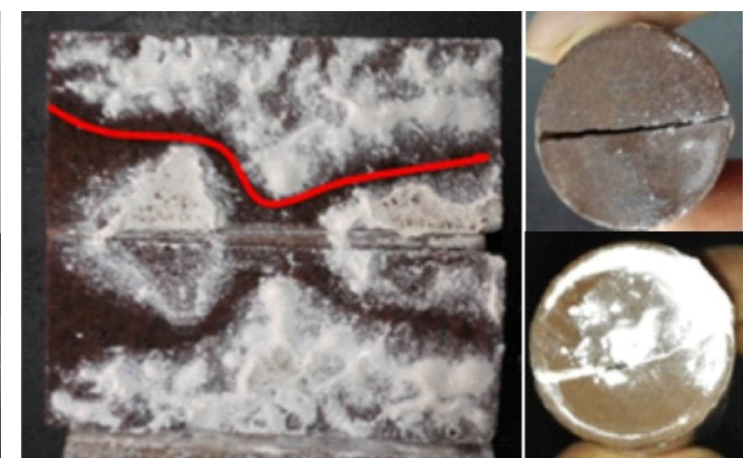

(b) After $\mathrm{BaSO}_{4}$ dissolution.

Fig. 12 Profile and the end surface morphology in microfracture before and after $\mathrm{BaSO}_{4}$ dissolution (No. A1). a Before $\mathrm{BaSO}_{4}$ dissolution. $\mathbf{b}$ After $\mathrm{BaSO}_{4}$ dissolution 


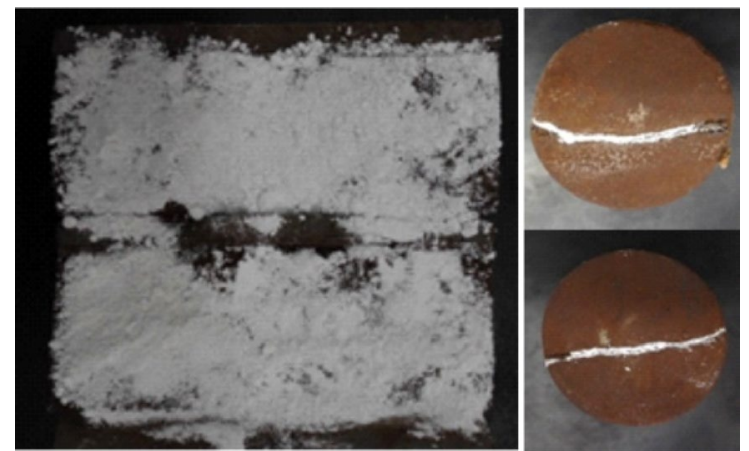

(a) Before $\mathrm{BaSO}_{4}$ dissolution.

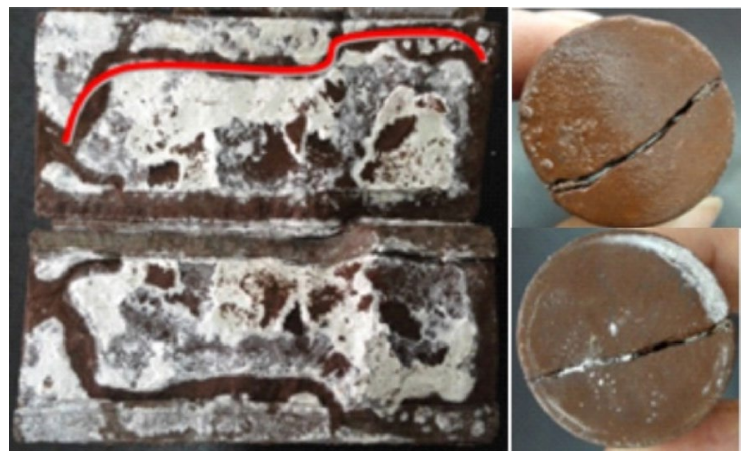

(b) After $\mathrm{BaSO}_{4}$ dissolution.

Fig. 13 Morphology of the profile and the end surface in a broad fracture before and after $\mathrm{BaSO}_{4}$ dissolution (No. A2)

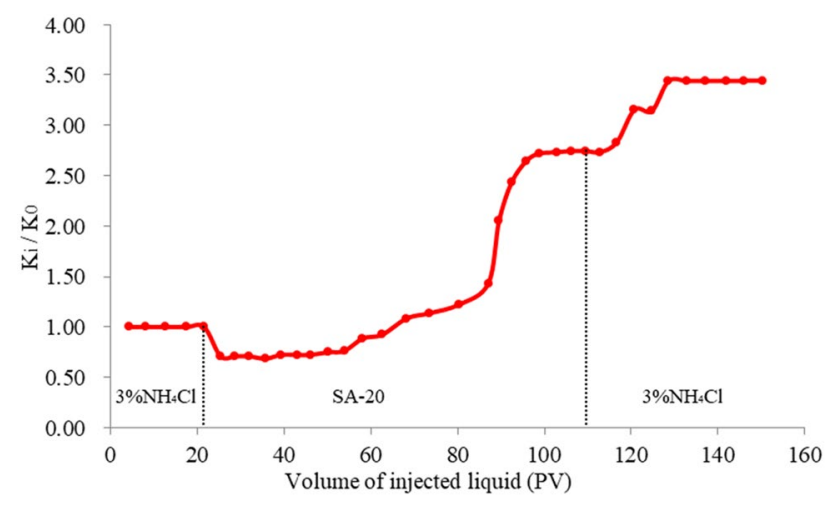

Fig. 14 Flow conductivity ability changes in microfracture before and after $\mathrm{BaSO}_{4}$ dissolution (No. A1)

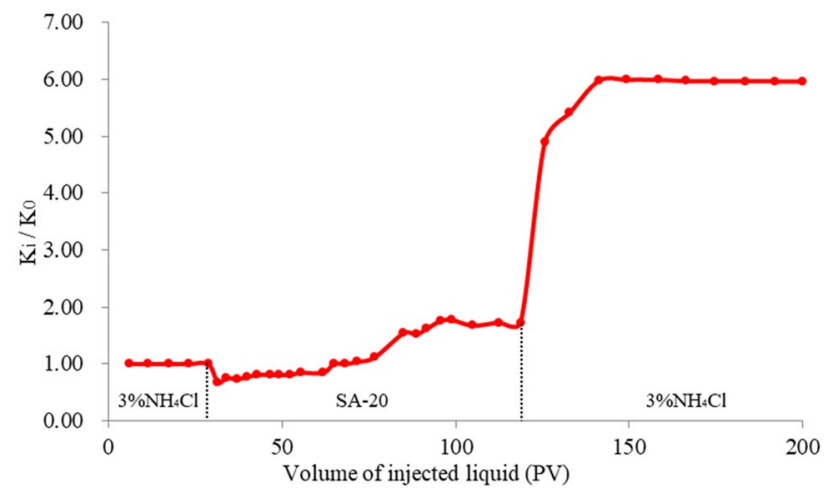

Fig. 15 Flow conductivity ability changes in a broad fracture before and after $\mathrm{BaSO}_{4}$ dissolution (No. A2)

respectively, illustrating that the SA-20 system possessed good blocking removal ability. Moreover, it also illustrated that the physical properties of the fractured reservoir with low porosity would be severely influenced after the damage of the barite. The oil and gas production enhancement

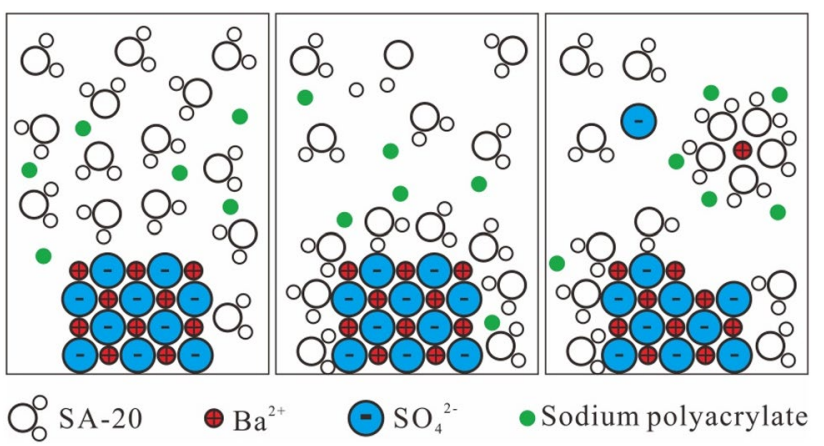

Fig. 16 Dispersion, chelation, and dissolution process of $\mathrm{BaSO}_{4}$ by SA-20

potential would be huge after the blocking removal procedure.

\section{Dissolution process and mechanism}

The blocking removal process of SA-20 included the softening and dissolution of $\mathrm{BaSO}_{4}$ solid phase and the dispersion and suspension of $\mathrm{BaSO}_{4}$ particles to form the solution by chelating function (Fig. 16). The $\mathrm{BaSO}_{4}$ dissolution mechanism by SA-20 mainly included chelation, lattice distortion, and dispersion.

\section{Chelating}

SA-20 was composed of the main agent of DTPA and the adjuvant of low molecular weight sodium polyacrylate. Figure 17 shows eight active coordination bonds, including three Ns and five Os in each molecule of DTPA, providing eight coordination bonds around a free metal ion. Thus, it was a good metal ion chelating agent. In alkaline solution, DTPA gradually changed into a negative ion cluster of DTPA ${ }^{5-}$. The resultant Ba-DTPA chelating product 
<smiles>O=C(O)CN(CCN(CC(=O)O)CC(=O)O)CCN(CC(=O)O)CC(=O)O</smiles>

Fig. 17 Molecular structure of DTPA

possessed high stability, whose chelating reaction equation is shown as follows:

$\mathrm{DTPA}^{5-}+\mathrm{Ba}^{2+} \rightarrow \mathrm{Ba}-\mathrm{DTPA}^{3-}$

The stability constant $\lg (\mathrm{Ksp})$ of the reaction of $\mathrm{DTPA}^{5-}+\mathrm{Ba}^{2+}=\mathrm{BaDTPA}^{3-}$ was 8.78 (Wang et al. 1999). The adjuvant low molecular weight sodium polyacrylate $(500-10,000)$ was electrolyte with functions of dispersion and scale inhibition. Thus, low molecular weight sodium polyacrylate was chosen as the adjuvant of SA-20 to realize both dispersion and blocking removal.

\section{Lattice distortion}

DTPA entered the crystal structure and distorted the lattice. The original structure changed, producing dislocation and distortion in the lattice. Figure 18 shows that the interaction between particles decreased, thus decreasing the hardness of $\mathrm{BaSO}_{4}$ that was made easier to be dispersed in the solvent (Darjani et al. 2019, 2017).

\section{Dispersion function}

The adjuvant of low molecular weight sodium polyacrylate was mainly used as the dispersive agent and the scale inhibitor. The corresponding relatively high charge density produced charge aggregation on the surface of the $\mathrm{BaSO}_{4}$ particles and the electric double layer as well as the resultant repulsion (Fig. 19).

The dispersion of particles into the fluid system of the blocking remover SA-20 increased the contact area between SA-20 and the blockage $\mathrm{BaSO}_{4}$, realizing the acceleration of the reaction rate. The addition of the dispersive agent of sodium polyacrylate in SA-20 was very effective for blockage removal. After the reaction between the blockage remover, which contained the dispersive agent, and $\mathrm{BaSO}_{4}$, the residue was transparent and had good dispersion effect,

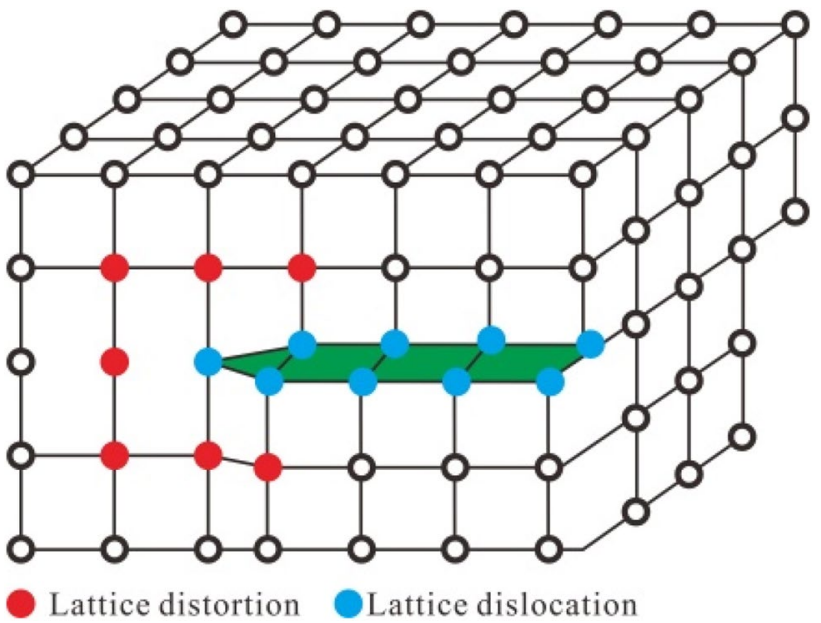

Fig. 18 Lattice distortion function

whereas after the reaction with the blockage remover, which did not contain the dispersive agent, the residue was in a state of muddy emulsoid with a large amount of unreacted $\mathrm{BaSO}_{4}$ and with a poor dispersion effect (Fig. 20).

\section{Conclusions}

(1)SA-20 was composed of the main agent DTPA and the adjuvant low molecular weight sodium polyacrylate. $\mathrm{BaSO}_{4}$ blocking could be effectively removed by the

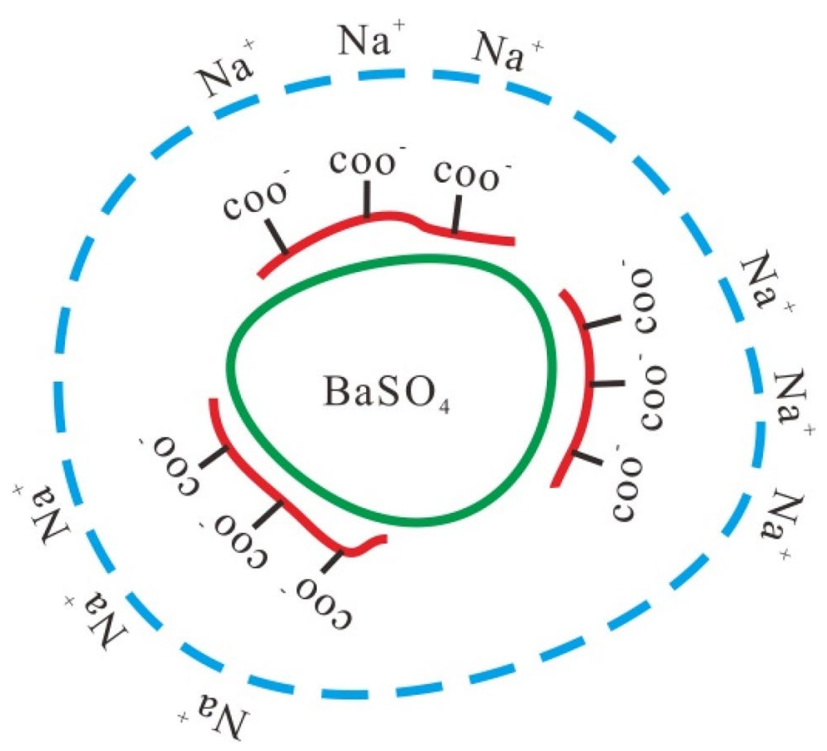

Fig. 19 Enhancement of dispersion ability due to the formation of the electric double layer of $\mathrm{BaSO}_{4}$ by sodium polyacrylate. a Residue with the addition of the dispersive agent of sodium polyacrylate. $\mathbf{b}$ Residue without the addition of the dispersive agent of sodium polyacrylate 


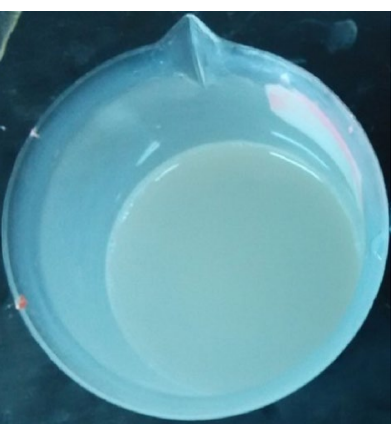
dispersive agent of sodium polyacrylate. (a) Residue with the addition of the

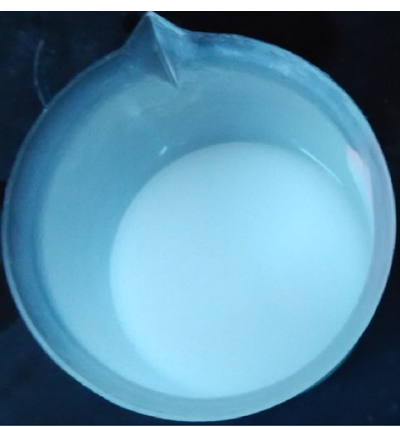

(b) Residue without the addition of the dispersive agent of sodium polyacrylate.
Fig. 20 The residue of the chemical reaction between blockage remover and $\mathrm{BaSO}_{4}$

chelating function and lattice distortion of DTPA, and the dispersion function of sodium polyacrylate.

(2)The influence of $\mathrm{pH}$, sodium polyacrylate concentration, and DTPA concentration on the dissolving ability of SA-20 was large, wherein the dissolving ability had a peak value. The dissolving ability increased with the increase in the reaction time and reaction temperature, though within a limit.

(3)Physical and chemical adsorption function occurred between sodium polyacrylate and $\mathrm{BaSO}_{4}$. The electric double layer on the surface of the particles could produce repulsion between particles, causing them to be in a state of dispersion and suspension. $\mathrm{BaSO}_{4}$ was thus dispersed and smashed. Due to the increased contact area between SA-20 and $\mathrm{BaSO}_{4}$ particles, the reaction rate and efficiency were greatly enhanced.

(4)The steel disk corrosion ability of SA-20 was extremely low, whereas the dissolving ability of SA-20 on $\mathrm{BaSO}_{4}$ was relatively high. The blocked $\mathrm{BaSO}_{4}$ in the fracture could be dissolved, forming a flowing passage with high conductivity ability, which thus increased the permeability of the fracture in the core.

Acknowledgements This work was supported by the National Natural Science Foundation of China (51974264), the National Science and Technology Major Projects (Grant No. 2016ZX05014, 2016ZX05052).

Open Access This article is licensed under a Creative Commons Attribution 4.0 International License, which permits use, sharing, adaptation, distribution and reproduction in any medium or format, as long as you give appropriate credit to the original author(s) and the source, provide a link to the Creative Commons licence, and indicate if changes were made. The images or other third party material in this article are included in the article's Creative Commons licence, unless indicated otherwise in a credit line to the material. If material is not included in the article's Creative Commons licence and your intended use is not permitted by statutory regulation or exceeds the permitted use, you will need to obtain permission directly from the copyright holder. To view a copy of this licence, visit http://creativecommons.org/licenses/by/4.0/.

\section{References}

Abib AP, G., da Cruz, G. and S.L. Vaz Junior, A., (2018) Study of barium sulfate dissolution by scale dissolver based on solutions of DTPA. Anais da Academia Brasileira de Ciências 90:3185-3196

Al-Yami AS, Nasr-El-Din HA, Al-Shafei M, Bataweel MA (2010) Impact of water-based drilling-in fluids on solids invasion and damage characteristics. SPE Prod Oper 25(1):40-49

Balanyà T, Labanda J, Llorens J, Sabaté J (2018) Influence of chemical speciation on the separation of metal ions from chelating agents by nanofiltration membranes. Sep Sci Technol 54:1-10

Bozau E, Häußler S, Berk W (2015) Hydrogeochemical modelling of corrosion effects and barite scaling in deep geothermal wells of the North German Basin using PHREEQC and PHAST. Geothermics 53:540-547

Darjani S, Koplik J, Banerjee S, Pauchard V (2019) Liquid-hexaticsolid phase transition of a hard-core lattice gas with third neighbor exclusion. J Chem Phys 151(10):1-11

Darjani S, Koplik J, Pauchard V (2017) Extracting the equation of state of lattice gases from random sequential adsorption simulations by means of the Gibbs adsorption isotherm. Phys Rev E 96(5):1-7

Egermann P, Longeron D, Lamy F (2002) A new methodology to derive both relative permeability and effective permeability reduction profile from numerical simulations of formation damage experiments. Pertophyiscs 43:347-357

Elkatatny S (2019) Mitigation of barite sagging during the drilling of high-pressure high-temperature wells using an invert emulsion drilling fluid. Powder Technol 352:325-330

Elshreef K, Lashin A (2016) Investigation of mud density and weighting materials effect on drilling fluid filter cake properties and formation damage. J Afr Earth Sci 117:345-357

Fang JKH et al (2018) Impact of particulate sediment, bentonite and barite (oil-drilling waste) on net fluxes of oxygen and nitrogen in Arctic-boreal sponges. Environ Pollut 238:948-958

Gál M, Kielar F, Sokolová R, Ramesova S, Kolivoska V (2013) Electrochemical study of the euiii/euii redox properties of complexes with potential MRI ligands. Eur J Inorg Chem 1:3217-3223

Jin H, Yang B, Yang S, He G (2014) An experimental and modeling study of barite deposition in one-dimensional Tubes. J Petrol Sci Eng 125:107-116

Liu F et al (2017) Mixture effect on the dilatation rheology of asphaltenes-laden interfaces. Langmuir 33(8):1927-1942

Luo Z et al (2019) Thermoresponsive in situ generated proppant based on liquid-solid transition of a supramolecular self-propping fracturing fluid. Energy Fuels 33(11):10659-10666

Mahmoud M et al (2018) Evaluation of the reaction kinetics of DTPA chelating agent and converter with barium sulfate (barite) using rotating disk apparatus. Energy Fuels 32(9):9813-9821

Mozaffari S et al (2017a) Colloidal nanoparticle size control: experimental and kinetic modeling investigation of the ligand metal binding role in controlling the nucleation and growth kinetics. Nanoscale 9(36):13772-13785

Mozaffari S, Tchoukov P, Atias J, Czarnecki J, Nazemifard N (2015) Effect of asphaltene aggregation on rheological properties of diluted athabasca bitumen. Energy Fuels 29(9):5595-5599

Mozaffari S et al (2017b) Capillary driven flow in nanochannels: application to heavy oil rheology studies. Colloid Surf Physicochem Eng Aspects 513:178-187

Nguyen T et al (2011) Experimental study of dynamic barite sag in oil-based drilling fluids using a modified rotational viscometer and a flow loop. J Petrol Sci Eng 78:160-165

Ratkievicius L, Filho F, Neto E, Santanna V (2016) Modification of bentonite clay by a cationic surfactant to be used as a viscosity 
enhancer in vegetable-oil-based drilling fluid. Appl Clay Sci 135:307-312

Shahbazi K, Mehta SA, Moore RG, Ursenbach M (2006) The effect of oxidation on viscosity of oil-based drilling fluids. J Can Pet Technol 45(6):41-46

Shaw SS, Sorbie KS (2015) Structure, stoichiometry, and modeling of mixed calcium magnesium phosphonate precipitation squeezeinhibitor complexes. SPE Prod Oper 30(1):6-15

Srungavarapu M, Patidar KK, Pathak AK, Mandal A (2018) Performance studies of water-based drilling fluid for drilling through hydrate bearing sediments. Appl Clay Sci 152:211-220

Uchida M, Sue A, Yoshioka T, Okuwaki A (2001) Morphology of barium sulfate synthesized with barium(II)-aminocarboxylate chelating precursors. CrystEngComm 3(5):1-6

Wang G, Du H, Zhang Z (2017) Viscous behavior and wall slip of barite-weighted water-based drilling fluids containing a high particle fraction. J Petrol Sci Eng 159:773-782
Wang K et al (1999) Dissolution of the barite (001) surface by the chelating agent DTPA as studied with non-contact atomic force microscopy. Physicochem Eng Aspects 160:217-227

Yan C et al (2015) Systematic study of barite nucleation and inhibition with various polymeric scale inhibitors by novel laser apparatus. SPE J 20(3):642-651

Zhang $\mathrm{F}$ et al (2016) Barite-scaling risk and inhibition at high temperature. SPE J 22(1):69-79

Publisher's Note Springer Nature remains neutral with regard to jurisdictional claims in published maps and institutional affiliations. 